\title{
Mujeres Palacio: la jugada con referencias lingüísticas y culturales de la mujer. Caso de actividad publicitaria de grandes almacenes mexicanos
}

\author{
Mujeres Palacio: the cultural linguistic game \\ with the stereotype of a woman. The case of the advertising \\ campaign for the Mexican department store
}

\author{
Edyta Kwiatkowska, Michat Faryś \\ Institute of Linguistics, Adam Mickiewicz University \\ ul. Międzychodzka 5, 60-371 Poznań \\ kedyta@amu.edu.pl
}

\begin{abstract}
For almost a decade Mexican department stores Palacio de Hierro have been running a media campaign called Soy Totalmente Palacio (I am totally the Palace). It is an image campaign, a novelty in the Spanish-speaking world, underpinned on playing with the linguistic and cultural stereotypes of a woman. The ads gained a broad social resonance and were followed up with a public debate on the image of a woman. The article presents types and ways of using the applied linguistic schemes and analyzes the mechanisms of the successful brand image building thanks to the use of stereotypes.
\end{abstract}

\section{Introducción}

Desde mas de una década los grandes almacenes mexicanos siguen una estratégica campaña de medios que ha incluido presencia en revistas, espectaculares, cine, prensa, radio y televisión, todo bajo el lema: Soy totalmente Palacio. La campaña, o más bien la controvertida imagen de mujer que presenta en los anuncios y los textos que la acompañan, ha levantado múltiples polémicas y genera varios debates nacionales e internacionales. Al mismo tiempo la campaña reforzó, con éxito, y renovó la marca de El Palacio de Hierro.

Desde el punto de vista sociolingüístico, la historia de la campaña refleja la explícita identificación del estereotipo con la imagen social de la mujer mexicana $\mathrm{y}$, simultáneamente, afirma los modelos de comportamiento y la valoración social de la imagen que presenta. Las protestas de los círculos feministas y crítica de la representación estereotipada de la mujer en la campaña publicitaria de El Palacio de Hierro $(\mathrm{PdH})$, por ser expresamente pronunciadas, paradójicamente, parecen al mismo tiempo promocionar aún más la marca objeto de la campaña. 


\section{Estereotipo lingüístico}

La lengua es un sistema ordenadamente variable, tanto sincrónica como diacrónicamente. Weinrich, Labov y Herzog afirman que un cambio lingüístico se inicia cuando una variante idiomática se generaliza en un subgrupo de una comunidad y adquiere una relativa significación social (1968). Según sociolingüistas, la innovación lingüística alcanza el estatus de estereotipo lingüístico. Cuando se realiza conscientemente por parte de los usuarios de la lengua, es un cambio desde arriba o cambio consciente; y si los cambios se difunden sin que los hablantes tengan conciencia de la innovación es un cambio desde abajo o cambio no consciente (Lara 2001).

Como un acto lingüístico, el estereotipo es una fórmula cristalizada o esquema no crítico que esquematiza y categoriza la realidad. Es rígido y resistente al cambio y, además, refleja la actitud idiomática de peyorización en el uso de la lengua.

En el uso moderno, un estereotipo presenta una imagen mental simplificada y poco detallada acerca de una clase de gente que comparte ciertas características cualidades y habilidades. Es un falso axioma de uso cotidiano, como el que dice que, por ejemplo, "las mujeres son cuerpo y los varones, mente". El tópico de las mujeres guapas y los hombres inteligentes es el más usado en los medios de comunicación, según múltiples autores (ver publicaciones online del Instituto de la Mujer).

Las manifestaciones de las referencias lingüísticas a la realidad social en su forma más sutil aparecen ya en las determinadas definiciones del diccionario. El Diccionario de la Real Academia Española de la Lengua (DRAE) en su actual vigésima tercera edición define lo masculino como "varonil, enérgico" ( $3^{\mathrm{a}}$ acepción), mientras que lo femenino es "débil, endeble" ( $6^{\mathrm{a}}$ acepción). No es sino impregnar los tópicos sociales y culturales recogidos por la lengua.

El estereotipo como artefacto lingüístico y proceso psicológico sustenta pues la discriminación y desigualdad. Siendo un acto mental no se somete al análisis racional.

\subsection{Estereotipo lingüístico de la mujer}

El estereotipo resulta siempre simplificador respecto al mundo que describe. No distingue entre los aspectos fundamentales y accidentales del elemento retratado (Allport 1968). Se observa también una retroalimentación entre el estereotipo y la realidad: la descripción lingüística de la realidad se fundamenta en el estereotipo, y -simultáneamente- esta misma imagen de la realidad confirma lo que ya se sabía, es decir, el propio estereotipo. Es la consecuencia de los atajos mentales y cognitivos que suponen los estereotipos (Bartmiński 2007).

Los estereotipos parten de una dualidad del modelo. Presentan o lanzan una dicotomía que implica siempre un contramodelo: "madre // suegra", "mujer sumisa // mujer perversa", "virgen // puta". Estos modelos trasmiten las imágenes, significados y comportamientos sociales junto con su reverso.

Como ya se ha marcado, en cada sociedad hay estereotipos que empobrecen la cultura pero simplifican la comunicación social. Este es el caso del tópico de la mujer, siempre cuando esta noción signifique el sexo o género como tal.

En tal entender, el ser mujer conlleva la pasividad y objetividad, sobre todo si es contrastado con la masculinidad. Evidentemente, el estereotipo abarca no solamente el sexo biológico, sino también el aspecto social del género (Mizielińska 1997). El llamado género cultural, diferente al sexo, aunque en su idea no determina socialmente como la dualidad biológica, y extrae las actividades sociales del contexto sexual, recurre al mismo repertorio de medios lingüísticos a la hora de comunicación (Deschamps y Devos 1996). Por eso, desde el punto de vista de la metodología de lingüística antropológica, la diferenciación entre el sexo y el género no tiene mayor importancia.

En términos generales, el estereotipo de sexo femenino se basa en la oposición al masculino. La descripción lingüística de la realidad parte de una antinomia: lo masculino está relacionado con el trabajo, resalta su aspecto público y tiene que ver con las actividades mentales, mientras que la feminidad reside en hogar, lo privado y lo corporal, siendo al mismo tiempo lo último lo menos relevante. Todos o casi todos reconocemos la "cosmovisión" patriarcal expresada por el lenguaje del discurso publicitario, impregnadora de los tópicos acerca de los roles sociales. No sorprende 
que en caso de una tan extensa campaña publicitaria de El Palacio de Hierro se haya partido de la mencionada imagen simplificada: de tal manera el mensaje publicitario, por muy controvertido que resulte, parece encajar en la realidad.

\section{El Palacio de Hierro: una nueva imagen de la empresa}

\subsection{Discurso publicitario}

La publicidad tiende a simplificar sus mensajes y propone imágenes asimiladas por sus receptores. $\mathrm{Su}$ propósito no es mostrar la complejidad de las cosas sino la mencionada imagen consensuada. Por razones de efectividad es pues el tópico el mejor mecanismo para cumplir con los fines del discurso publicitario: trasmitir el sentimiento de seguridad del mensaje, sin recurrir o centrarse en la razón y la lógica del comunicado.

Las narraciones de anuncios publicitarios y sus protagonistas aparecen siempre en una forma simplificada pero cargada de significado. Siguiendo a Barthes, podría decirse que un buen mensaje publicitario "condensa en sí mismo la retórica más rica" (1990: 242). Los elementos del estilo textual que puedan ampliar el significado del comunicado pueden aprovecharse en la publicidad: metáforas, juegos de palabras, símiles u otras figuras retóricas. Al mismo tiempo, el usar en la publicidad el recurso simplificador del estereotipo facilita decir el producto, contando otra cosa. El mensaje publicitario está connotado ya que nos anima a comprar, está también denotado y nos hace entender que precisamente este mundo de compras es donde los sueños de cada persona se cumplen.

Los registros de estereotipos automáticamente levantan las mismas emociones y designan las cualidades deseables. No obstante, al mismo tiempo pueden dar lugar a nuevas interpretaciones, incitando al público a identificarse con su mensaje o oponerse a él.

Como el estereotipo evita el razonamiento, es el perfecto instrumento de conseguir el objetivo de la publicidad: ayuda a clasificar, decidir cosas a corto plazo y detectar rápidamente los objetivos del mensaje. Al mismo tiempo, siendo punto de partida, motiva la exploración de un asunto y búsqueda de una reflexión más elaborada. En todas estas cualidades se funda la campaña Soy totalmente Palacio.

\subsection{Historia de la campaña}

La campaña publicitaria Soy totalmente Palacio ha sido elaborada y dirigida por la agencia mexicana Terán TBWA. En la página oficial de la agencia se puede identificar su política de negocio:

Nosotros creemos en el poder de las ideas: el poder de las ideas para cambiar el mundo y el poder de las ideas para impulsar las marcas. Sin embargo, esto genera una búsqueda continua ya que alguien alguna vez dijo que no hay nada que falle de una manera más espectacular que un éxito. En otras palabras, el seguir haciendo lo que funcionó otras veces en el pasado. (www.terantbwa.com.mx).

Cuando en 1995 Ana María Olabuenaga inventa el eslogan: Soy totalmente Palacio, desde su primera publicación establece nueva época en la vida del sector publicitario nacional. Inventa una frase exitosa que recurre a todos los elementos mencionados anteriormente: su construcción retórica mantiene al mismo tiempo una fuerte relación sentimental y es socialmente consensuada, tanto con la marca, como con la autodeterminación de la mujer mexicana.

Como afirma la agencia publicitaria Terán TBWA el compromiso creativo con El Palacio de Hierro tiene una historia muy significativa. Es en el Palacio de Durango donde hace sesenta años, en 1947, José Terrán abre el Estudio de Arte, cuyo cliente fundador es PdH. Por lo tanto, los lazos profesionales entre las dos empresas no se pueden ignorar. Aunque hoy en día la agencia es una empresa multinacional, el mayor éxito y fama le traen las sucesivas realizaciones publicitarias de la campaña $\mathrm{PdH}$, o - en muchos casos- las polémicas que éstas levantan.

El Palacio de Hierro el mercado nacional es una de las redes de tiendas departamentales, no desprovista de la competencia fuerte, por ejemplo de Liverpool. Los objetivos la campaña en cuestión eran causar que el PdH se perciba más de calidad y más de lujo que las demás tiendas. El Palacio de Hierro maneja marcas importadas de la mejor calidad, crea ambiente de exclusividad 
y es percibida principalmente para mujeres a pesar de que su variedad de productos es muy extensa.

La agencia publicitaria que ha manejado la imagen de El Palacio de Hierro confirma que el eslogan Soy totalmente Palacio tenía por objeto reforzar el posicionamiento de la tienda y lograr que el mercado femenino se sienta identificado con la misma. El éxito de la campaña ha sido inesperadamente fuerte y lo más importante es que tiene un impacto muy positivo en el aumento de las ventas de esta tienda departamental.

La campaña ha contado con los especialistas más renombrados del sector: la autora creativa es Ana María Olabuenaga y los principales fotógrafos que prestaron su talento para este trabajo son, entre otros Albert Watson y Howard Schatz. Efectivamente, Soy totalmente Palacio ha sido una de las campañas más ovacionadas en el mundo de la publicidad. Ha sido premiada en diferentes festivales: ha obtenido el Premio a la Campaña de Campañas, otorgado por la Asociación de la Publicidad; ha sido ganadora de la medalla de plata en The New York Festival para gráfica; y ha ganado 12 premios en el Círculo Creativo de México, que incluyen televisión, carteleras, prensa y revistas.

\section{$4 \quad$ Los mensajes publicitarios}

\subsection{Estructura formal}

La lema: Soy totalmente Palacio ha creado alrededor de sí una idea prefabricada de la mujer. No obstante, al aplicar los más comunes fraseologismos y estereotipos sobre el sexo femenino, se está abandonando su valoración tradicional.

El núcleo y la base del éxito de la campaña de PdH es precisamente este eslogan, la confesión: Soy totalmente Palacio. Aplicada en cada publicidad representa un prototipo de mujer que se dirige a las demás mujeres.

Ya se ha dicho que el estereotipo surge de los determinados roles sociales, es decir además de servirse de unos tópicos genéricos de lo femenino, recurre al del conjunto de actividades adscritas a cada sexo en el contexto social. La publicidad de PdH lo aplica de dos maneras: partiendo de la citada identificación de la marca con el tipo de la mujer perfecta aprovecha dos mecanismos: (1) refuerza el tópico de lo femenino y el rol social de la mujer, o (2) lo desmiente.

Así lo que es femenino: mujer, niña, esposa, presentado en su entorno de siempre y las actividades cotidianas más comunes, adquiere un valor positivo. Lo masculino: esposo, hombre, psicoanalista, príncipe, aunque no pierde sus características tradicionales, deja de emanar los valores presentados como superiores, lo masculino se somete al control y la buena voluntad de lo femenino.

El eslogan de la campaña no rompe con la imagen de la mujer en la publicidad. Lo explota y lo presenta sin ninguna modificación formal. Lo nuevo, sin embargo, es que lo valora de manera completamente diferente. Los vicios de las mujeres y su comportamiento típico conllevan un claro valor positivo.

En cuanto a la estructura formal de los mensajes, la idea es que todas se parezcan formalmente. El texto publicitario está basado en un mensaje determinado seguido por una frase común. Cada serie de mensajes publicitarios que forman parte de la campaña tiene pues la misma estructura formal:

\section{texto original único + Soy totalmente Palacio}

El contenido de la frase original única es siempre un estereotipo o un fraseologismo relacionado con los clichés sociales universales. Refuerzan los tópicos, están lejos de representación constructiva ni plantean alternativas igualitarias. Su finalidad es presentar los roles y estereotipos que aparentemente limitan las funciones de la mujer en la sociedad, pero al mismo tiempo indican que estas funciones no reducen para nada las oportunidades de realizar sus deseos y dirigir sus vidas libremente. Con el eslogan: Soy totalmente Palacio indican la valorización positiva de dichos clichés. 
Las "verdades" acerca de la mujer se complementan en los anuncios con imágenes modelos sobre fondos que corresponden a los textos empleados. En caso de publicidad televisiva se emplean las tramas e imágenes para presentar, en calidad de desenlace o moraleja, una enunciación, muchas veces inesperadamente absurda, acompañada por el eslogan de la campaña.

\subsection{Las referencias a la mujer: contenido semántico y retórico}

En el estudio de significado de los determinados ejemplos es conveniente agruparlos según el contenido semántico común y los recursos estilísticos aplicados. Entre todas se presentan los que a lo largo de los años han captado más atención. La presentación a continuación parte pues de la imagen la mujer que evocan, independientemente de las características estructurales de los componentes de las frases (Bartmiński 1998). Entre paréntesis se indica el año de la introducción de dicha frase como parte del mensaje publicitario, tanto en prensa, como en la televisión. Cada uno de estos comunicados concluye, como ya se ha dicho, con el lema de la campaña: Soy totalmente Palacio.

\subsubsection{Palacio es lujo}

La campaña parte del juego de palabras con el nombre propio de los almacenes. El "Palacio de Hierro" en del mensaje publicitario es un verdadero palacio y es realmente de hierro. Cada frase de la campaña hace reflexionar sobre sus componentes y pretende evocar lo positivo de "palacio" y de "hierro". Un palacio se asocia normalmente con magnificencia, tesoros y secretos. El palacio es el lugar del rey, el refugio de las riquezas, simboliza poder y fortuna. Es esencial el lugar y no el varón que lo habita: Cada vez hay menos príncipes; por fortuna, cada vez hay más Palacios (1999).

Los palacios también constituyen una fuente de armonía material, individual y social. Son centros de atención para los lugares donde están construido, para el rey que lo habita y para el pueblo que lo contempla. Si a estos atributos se agrega el hecho de que el palacio está hecho de hierro, el lugar adquiere un aire de la modernidad resultante de una fusión entre la magnificencia que podría corresponder a tiempos pasados, y la comodidad y tecnología de los actuales.

Las mujeres que habitan este almacén son totalmente Palacio. Mujeres "independientes" y "liberales" que, en lugar de concertar citas con el psicoanalista, curan sus problemas comprando vestidos nuevos (Porque un psicoanalista nunca entenderá el poder curativo de un vestido nuevo (1997)), y -conforme al mensaje- comen con los ojos para ser más perfecta (Porque la mejor forma de guardar la línea es comer con los ojos (1997)) o alcanzan la felicidad infinita cuando consiguen algo nuevo: Porque nadie ha logrado envasar el olor a nuevo (1997).

Conforme con la imagen que pretenden evocar y mantener los mensajes de la campaña, las mujeres totalmente Palacio no sólo viven de lujo, ellas representan el lujo, son la emanación del lujo: Si estas viva, vive totalmente Palacio (2007).

\subsubsection{Lengua en uso}

En la campaña se recurre a la representación retorcida de ciertos tópicos, sobre todo si el mensaje está construido a base de un fraseologismo, como el anteriormente citado "comer con los ojos". Las jugadas lingüísticas con las expresiones fijas o frases hechas a rebour constituyen un recurso bastante frecuente.

Por ejemplo, en el anuncio encabezado por el enunciado: Los caballeros no tienen memoria pero nunca olvidan un buen perfume (2006), la expresión de "no tener memoria", además de denotar "discreción", mantiene su significado literal. "No tener memoria" es en este caso sobre todo: "carecer de memoria, olvidarse de las cosas", y de esta manera el mensaje adquiere un significado nuevo y más pleno: el lujo (es decir, el buen perfume) es indispensable para que el varón tenga presente en la mente a la mujer con la cual estuvo.

Es obvio que los juegos de palabras en los enunciados empleados en la publicidad tienen mérito creativo. Por ejemplo, cuando se usa la frase: Porque sólo una buena esposa evita ir mucho de compras (1997), los anuncios muestran a una mujer esposada para evitar que escape corriendo a comprar, jugando así con la ambivalencia de la palabra "esposa". 
Algo parecido sucede en la frase que aprovecha la homonimia del sustantivo "ama" y la forma personal del verbo "amar": Lo curioso es que lo que ama un ama de casa son las tiendas (1998). Simultáneamente, se contraponen los sustantivos de "casa" y "tienda".

De hecho, el recurso de antítesis es uno de los más frecuentes, tanto al nivel de lexemas como al nivel de sintagmas. Se observa en una serie de comerciales que recurren a conceptos contrapuestos:

$>$ Sexo débil // sexo fuerte: Por suerte somos el Sexo Débil, el fuerte es el que carga las compras (1999)

$>$ Lo externo // lo interno: La prueba de que no somos superficiales, es que también nos preocupa nuestro interior (2000)

$>$ Oir // hablar: Es verdad que las paredes oyen, por suerte los probadores no hablan (2001)

$>$ Realidad // sueño o cubrir // descubrir: La ropa cubre lo que eres y descubre ol que quieres ser (2001)

$>$ Sobrar // faltar: A las mujeres siempre nos sobran kilos y nos falta ropa (1998)

$>$ No buscar // encontrar: Lo maravilloso de las tiendas es que siempre encuentras, lo que no andas buscando (2000).

$>$ Ropa nueva // ropa vista: El problema no es que me quede bien o mal, sino que ya me lo vieron (1999).

Los símiles como recursos parten de la imagen común de la mujer vanidosa y superficial: La firma de un diseñador es como el amor: no se puede ocultar (2003).

Las metáforas usadas en la campaña forman parte del repertorio universal de comportamiento genérico: la mujer es una niña: Sólo una frase separa a la niña de la mujer: no tengo nada que ponerme (1998), es una pecadora nata y perversa: Quizá no me vaya al cielo pero un par de tacones me acercan (2005), o Si te vistes para matar, prepárate para ver a alguien morir de amor (2001). Además, explotan la actitud femenina de relación emotiva y personificadora con los objetos: Si las medias supieran la angustia que causan cuando se van, quizá regresarían (2001).

\subsection{Elementos tópicos: referencias genéricas y culturales}

Lo femenino es el término genérico y según las tendencias actuales no tiene una relación exclusiva con la mujer. No obstante, en caso de la mayoría de las sociedades, incluida la mexicana, jerarquizada fuertemente e indudablemente patriarcal, los procesos sociales de convertirse en masculinos o femeninos se perciben comúnmente como el desarrollo de los roles biológicos de cada sexo. Por lo tanto el estereotipo cultural de la mujer es muy definido. Ya se ha mencionado que principalmente consiste en el otorgamiento de las propiedades, capacidades y creencias femeninas en el proceso de socialización de las niñas. Esta señalización de comportamientos típicos marca la diferencia entre los sexos. Por lo tanto la mujer en la sociedad (no verdadera mujer, sino la típica, según lo expone Bartmiński 1998) realiza las actitudes típicamente femeninas de inferior valolación, mientras que lo que caracteriza a un individuo masculino se puede delimitar con trabajo, posición social superior, dominio público y la mente. La tipificación del rol femenino, explotado en la campaña de $\mathrm{PdH}$, enumera que la mujer:

$>$ se ocupa del hogar: Si las mujeres no fueran de compras, los hombres no tendrían calcetines (2002)

$>$ mantiene una posición social inferior: Una mujer no sabe lo que quiere hasta que un diseñador se lo dice (2005)

$>$ e mueve principalmente en el dominio privado: Ninguna mujer sabe lo que quiere, hasta que se lo ve puesto a otra (2002)

$>$ su principal expresión y su intimidad reside en el cuerpo: Si preguntas mi talla, preferiré contestar mi edad (2000).

Dado que en el discurso publicitario la economía mental juega un papel determinante, el uso de susodichos estereotipos genéricos parece natural. Por otro lado, la campaña de PdH está lejos de la discriminación y diferenciación injusta de los sexos: los textos de sus anuncios, aunque parten del estereotipo de la mujer, no permiten que se realice una categorización automática del mensaje, porque éste está construido de tal manera que provoca una fuerte reacción emotiva. Aparte 
de una reflexión lingüística cuando los fraseologismos dejan de significar lo que automáticamente pensamos (como en el ejemplo: El amor a primera vista existe. Basta pararse frente a un escaparate (1999)) se trata de las conscientes aprobaciones entusiásticas del mensaje o reacciones de sorpresa que llevan a la identificación del público con la imagen presentada: Las mujeres tenemos el vicio de comprar y es que no podemos ser perfectas (1999).

El Instituto de la Mujer en su Guía Mujeres y hombres por la igualdad (1998) presenta cuatro tipos de anuncios publicitarios que contradicen la idea de igualdad entre sexos y por lo tanto deben de erradicarse del mundo publicitario. Denuncia como poco respetuosas (1) las publicidades que promueven modelos tradicionales de hombres y mujeres en su participación en la vida social, política y económica, (2) las que presentan a la mujer como incapaz de controlar sus emociones. También considera que (3) los tópicos sobre las imperfecciones del cuerpo femenino y la necesidad de corregirlas por el continuo seguimiento de modelos de belleza imposibles de conseguir. Denuncia que es discriminatoria (4) la presentación de la mujer como una persona en posición de inferioridad o dependencia.

Los cuatro tipos enumerados i denunciados por las entidades sociales de formación en igualdad entre hombres y mujeres fueron aplicados a propósito en la campaña de PdH. Si lo detallamos, tenemos una lista de cualidades que aparecen en la publicidad fundada en tópicos. La mujer del estereotipo cultural es:

$>$ sumisa: Si te digo que no me pasa nada, o no tengo nada, no me creas nada (2002)

$>$ dependiente: Jamás estas ni demasiado bien vestida, ni demasiado amada (2003)

$>$ pasiva: Sólo estoy viendo, en realidad quiere decir "no me despierten, estoy soñando" (2001)

$>$ sigue y no dirige: Una mujer no sabe lo que quiere hasta que un diseñador se lo dice (2005)

$>\quad$ insegura de sí misma: Es más fácil conquistar a un hombre que a un espejo (1998)

$>$ no tiene verdadera ambición: Ninguna mujer sabe lo que quiere, hasta que se lo ve puesto a otra (2002)

$>$ es sensible, sobre todo a los sentimientos de los demás: Yo sé cómo me veo. Si pregunto es para saber cuánto te gusto (2000)

$>$ es excesivamente emotiva: hay dos cosas que una mujer no puede evitar: llorar y comprar zapatos (1998).

Los comerciales de $\mathrm{PdH}$ reproducen una imagen de la mujer que el público considera verdadera, por ser típica. Sobre todo invita a las mujeres que apliquen la explicación que proporciona el anuncio. Los personajes femeninos de la publicidad de $\mathrm{PdH}$ son mujeres del tópico, no tienen mucho que ver con la realidad social de México. Corresponden no obstante al tipo de la mujer universal en su comportamiento y carácter. Esta operación sirve para que las receptoras nacionales al final se puedan identificar con el prototipo de la mujer de Palacio, que puedan sentirse parte del Palacio, es decir considerarse un sujeto/objeto deseado y lujoso. Que se vean reforzadas con los mensajes como las siguientes: Yo sé cómo me veo. Si pregunto es para saber cuánto te gusto (2000) o Las mujeres siempre supimos que un cambio de ropa nos hace poderosas (2006). El Palacio seduce y ser una de las mujeres Palacio supone asociarse al grupo poderoso a cuyo alcance se encuentran las mejores herramientas para alcanzar la felicidad: Ni un hada madrina te saca de tantos apuros como un vestido negro (2002) o Soy talla 3: no hay rival que se resista a eso (2004).

En el Palacio la vanidad constituye una de las cualidades indispensables y de tal modo deja de connotar un comportamiento negativo o desaprobable. Las mujeres de Palacio son vanidosas y egoístas, y no paran de ostentarlo: El amor a primera vista existe. Basta pararse frente a un escaparate (1999), No lo olvides: lo tuyo es mío y lo mio es mio (2004) y, finalmente, Las tiendas existen porque la vanidad nunca muere (2002).

La explotación de la supuesta diferencia social y cultural, denunciada por las feministas, ha sido perfectamente aplicada en la publicidad de PdH. Su mensaje fue claro y favorecedor. Las mujeres de Palacio son las que aceptaron su rol social y lo explotan con gusto y sin reparo: Las mujeres queremos más que los hombres, por eso compramos más (2001), o Las mujeres tenemos el vicio de comprar y es que no podemos ser perfectas (1999). 


\section{Debate social sobre las mujeres Palacio}

La publicidad recurre a diferentes mecanismos de captación, motivación y persuasión. Los tópicos que normalmente son considerados como discriminatorios, en caso de la campaña publicitaria de PdH, se manipulan para que los espectadores puedan considerarla interesante y agradable.

La campaña de $\mathrm{PdH}$, totalmente dirigida a la mujer, gracias a las frases compuestas que se basan en atajos cognitivos, indica a todo público, masculino y femenino, que las mujeres son simplemente así. Además, los hombres, influidos por la campaña, identifican a sus parejas con los modelos de la publicidad. En consecuencia reconocen que son ellas las que se encargan de las compras, admiten que las compras forman parte de la identidad femenina y aceptan que esta actividad es un sinónimo de lujo.

Se ha dicho que el tópico de la mujer está fundado en la dualidad del significado. El éxito de la campaña PdH consiste en aprovechar la polarización y asociar los modelos de siempre con sus características contrarias, se da una vuelta al tópico: las imágenes que funcionan con la connotación negativa adquieren rasgos positivos, y por otra parte, se desvela la falta de valor de las imágenes que hasta el momento parecían positivas, por ejemplo: ¿Quién es la vanidosa, la que se arregla o la que cree que así está bien? (2000) o Ningún hombre conoce la respuesta correcta a: "¿me quieres?" y "¿cómo me veo?" (1999).

Mientras cierto tipo de publicidad se preocupa por acabar con discriminación por sexo en sus campañas y evitan tópicos que refuerzan roles sociales de la mujer, otras, como la campaña publicitaria de $\mathrm{PdH}$, al usar estereotipos en los anuncios, emite un comunicado que impulsa a las mujeres que sigan identificándose con su rol, siempre en su carácter exclusivo y lujoso. El mensaje latente de los anuncios de $\mathrm{PdH}$ es, sin duda, la identificación femenina con el marco.

\subsection{Crítica y anticampaña}

La crítica de la publicidad de El Palacio de Hierro, desde su inauguración en 1997, ataca sobre todo la idea de aprovechar la imagen fácil de la mujer típica, basada en una serie de tópicos (1) basados en la visión patriarcal del mundo y (2) muchas veces alejados a la verdad social mexicana. Denuncia no tanto el hecho de aprovecharse de las cualidades estereotipizadas de las mujeres, sino que la imagen presentada no tiene mucho que ver con la realidad del país y poco que ver con el perfil de las posibles clientes de los grandes almacenes. La mujer de los carteles de PdH es emocionalmente inestable, abiertamente sólo piensa en sí y en la compra. Las críticas también subrayan que la prototipo de la mujer de Palacio es representada por la mujer blanca y joven, una modelo diferente al tipo de una persona de la clase alta o de las demás posibles clientas. Sin embargo, si el mercado meta de El Palacio de Hierro son mujeres ricas, la publicidad de PdH también se dirige al público de clase media, ya que son principalmente ellos los que consumen la televisión.

Los debates sobre el motivo de la publicidad transcurren sobre todo en los foros de Internet dedicados a los asuntos de igualdad de sexos y el estatus social y laboral de la mujer mexicana. En una de las opiniones su autora acusa la publicidad de El Palacio de Hierro como una manera de degradar las cualidades de mujer. Y confiesa: "Yo dejé de comprar ropa en esta empresa, ya que no me siento identificada con publicidad con frases que denigran la inteligencia de nosotras" (http://sepiensa.org.mx/contenidos/f_hierro/c_comentarios1.htm).

Thelma Alcántara, en el artículo introductorio expresa su desprecio a la campaña ridiculizando uno de sus anuncios: "es difícil imaginarse el país completamente desierto y encontrar a todas las mujeres en un verdadero mar de lágrimas abarrotando las zapaterías en inevitables y masivos ataques de compras, porque hay dos cosas que una mujer no puede evitar: llorar y comprar zapatos" (http://sepiensa.org.mx/contenidos/f_hierro/hierro3.htm).

Del otro lado, la campaña publicitaria de El Palacio de Hierro es un ejemplo de un tendencia en los medios de comunicación que consiste en cierta desacralización de la mujer que hasta entonces se presentaba en su principal papel de esposa y madre. Este tópico, muy explotado, sigue comúnmente aceptado como el modelo cultural y lingüístico de la mujer. Es importante esta observación, ya que la publicidad tiene una potente capacidad sancionadora de categoría 
de existencia real que concede a lo que es apenas un discurso. La publicidad se aprovecha de la facultad ambigua de la lengua: lo expresado es real, mientras que lo no expresado no existe.

Es evidente pues que cualquier anticampaña intente levantar estas cuestiones para introducir en debate el verdadero papel cultural de lo femenino. Es el caso de Lorena Wolffer que en el año 2000 inició una crítica en contra de la campaña publicitaria que a su juicio promueve el consumo, $\mathrm{y}$ al mismo tiempo fomenta valores que resultan insustanciales y son principalmente humillantes y estereotipados (Ordoñez 2007).

Wolffer coloca diez carteleras espectaculares similares a las de PdH tratando este medio como la manera de contrarrestar la influencia de los cientos de anuncios que invaden el horizonte urbano (Springer 2000). Los carteles diseñados por ella muestran a la mujer cotidiana que habita los espacios comunes de la ciudad: escuela, transporte público y las calles. Wolffer adopta los elementos del mensaje que presentan los anuncios de El Palacio de Hierro, pero lo resignifica (véanse las muestras de sus billboards en Springer): en su propuesta las mujeres dejan de ser Totalmente Palacio y pasan a ser Totalmente de Hierro. Indican el verdadero rol femenino y sus circunstancias sociales: Ninguna campaña publicitaria es capaz de silenciar mi voz, El problema es que pienses que mi cuerpo te pertenece, Lo curioso es que creas que puedes controlar mi imagen o ¿Quién te enseña cómo ser mujer?, para presentar los comunicados más llamativos. Cada una de estas frases es acompañada con la imagen de la propia artista y el lema común: Soy totalmente de hierro.

De esta manera la imagen artística crea una nueva óptica para la lectura de los anuncios de PdH acudiendo a la memoria del espectador para que éste pueda entender la finalidad contestataria de la artista. La campaña de Wolffer, en comparación a la campaña de El Palacio de Hierro, duró muy poco tiempo y contó con sólo diez carteles, no obstante fue lo suficiente llamativa para lograr una buena difusión.

\subsection{Mujeres, las que somos Palacio}

Una de las previsibles respuestas a la campaña de El Palacio de Hierro es la creación de vínculos fuertes con el producto, es decir con la marca PdH. La seña de identidad de la Mujer Palacio depende de su estatus social y económico, no obstante es comúnmente reconocible: las mujeres de clase media ostentan las bolsas con el anagrama de El Palacio de Hierro, mientras que las de clase alta aseguran su identificación con la marca gozando de la Tarjeta Palacio de compras exclusiva de PdH. El símbolo de El Palacio de Hierro en forma de nuevo diseño de la bolsa de compra, lanzado en 2006, ha sido también un elemento de debate sobre los elementos de las estrategias de posicionamiento de la marca. Una vez más, el El Palacio de Hierro ha comprobado entonces el impacto social que ejerce, logrado gracias a la campaña publicitaria de Terrán.

El paso más adelante, lo constituyen las estrategias modernas relacionadas con los eventos públicos. Por ejemplo, El Palacio de Hierro en la consecuente creación de su marca, fundada en la imagen de lujo y vanidad, auspicia en 2007 las carreras de tacones. La explotación del tópico de la mujer en este caso ha sido llevada al extremo. El conocido blog feminista mexicano que usualmente denuncia los abusos contra la mujer reproduce todo el anuncio (http://mujeresinsumisas.blogspot.com/2007/10/carreras-en-tacones.html):

La Revista Fernanda y El Palacio de Hierro tienen el agrado de invitarte a participar en esta divertida y singular competencia, única en México. Así inicia la promoción de una "carrera de tacones" que pretende llevarse a cabo el próximo 28 de octubre en la ciudad de México. La "divertida y singular competencia" consiste en que mujeres mayores de 25 años corran 100 metros, certificados por la Federación Mexicana de Atletismo, en la Avenida Horacio de la colonia Polanco, usando tacones de aguja que midan por lo menos 7 centímetros y hasta un máximo de 10.5 centímetros.

Las competidoras de dicha carrera podían ser, conforme a la filosofía de $\mathrm{PdH}$, "mujeres por naturaleza" cuyo esfuerzo se premiaba con los regalos lujosos. Además, en la mencionada convocatoria aparecieron más informaciones bajo el subtítulo "¡Ponte muy guapa y gana más premios!", que indicaron que después de la carrera, las competidoras podían seguir concursando por los títulos de "El mejor peinado", "La más elegante" y "La mejor sonrisa". 


\section{A modo de conclusión}

Los anuncios publicitarios marcan modelos y patrones que son interpretados de diferente manera por los espectadores $\mathrm{y}$, por lo mismo, pueden inducir a ciertas prácticas discriminatorias, estereotipadas y sexistas (Instituto de la Mujer 1998). No obstante, si los medios de comunicación admiten o aplican el conjunto de imágenes estereotipizadas es porque el público lo comparte, lo entiende y lo acepta.

Al mismo tiempo, las campañas como la de El Palacio de Hierro fomentan la aparición de patrones culturales y sociales.

Hay que reconocer, no obstante, que el caso de $\mathrm{PdH}$ es un caso de importancia mundial. Ha sido i sigue siendo una fuente de inspiración para los artistas de cultura popular y el objeto de debate de todas las clases sociales en México. Además, fue una actividad de gran calidad en cuanto a los aspectos de su realización y ha tenido un gran impacto en la innovación de las tendencias de la publicidad de moda.

Después de todo, lo más llamativo y digno de subrayar de la campaña Soy Totalmente Palacio radica en que este tipo de publicidad replantea seriamente el papel que el lenguaje publicitario juega en la formación de la sociedad. Indica también cómo una sociedad puede influir y participar en la formación y la crítica de los medios. Eso sí: siempre cuando le compensa. No nos olvidemos pues que las mujeres Palacio, según sus propias palabras, pueden tener otros objetivos: Te daría mi vida pero la estoy usando (2003). 


\section{Bibliografia}

Alcántara, T. Mujeres Totalmente Palacio. @: http://sepiensa.org.mx/contenidos/f_hierro/hierro3.htm [octubre 2007]. Allport, G. W. 1968. La naturaleza del prejuicio. Buenos Aires: Eudeba.

Barthes, R. 1990. La aventura semiológica. Barcelona: Paidós.

Bartmiński J. 2007. Stereotypy mieszkaja w języku. Studia etnolingwistyczne. Lublin: Wydawnictwo UMCS.

Bartmiński, J. 1998. Podstawy lingwistycznych badań nad stereotypem na przykładzie stereotypu matki. Jezzyk a Kultura, Stereotyp jako przedmiot lingwistyki. Teoria, metodologia, analizy empiryczne, vol. 12. pp. 63-83.

Deschamps, J. C. y Th. Devos, Relaciones entre identidad social e identidad personal. En: Identidad social. Aproximaciones psicosociales a los grupos y a las relaciones entre grupos, Valencia: Promolibro. pp. 39-55.

El Palacio de Hierro. Página web de la tienda departamental @: http://www.elpalaciodehierro.com.mx/ [octubre 2007].

Fundación Mujeres: S. Castaño de la Cruz, C. Garoía Comas, N. Gomaiz Moraga. 1998. Mujeres y hombres por la igualdad. Madrid: Instituto de la Mujer. @: http://www.mtas.es/mujer/publicaciones/docs/materiales_digital.pdf [octubre 2007].

Lara, L. F. 2001. Ensayos de teoría semántica: lengua natural y lenguajes científicos, Madrid.

Mizielińska J. 1997. Kobieta jako przedmiot i podmiot reklamy”. En Od kobiety do mężczyzny i z powrotem - rozważania o ptci w kulturze. Białystok: Trans Humana.

Mujeres insumisas. Blog feminista mexicano @: http://mujeresinsumisas.blogspot.com [octubre 2007].

Ordoñez, S. 2007. El uso capitalista en serie del cuerpo de la mujer en Ciudad Juárez. El cuerpo como representación del poder. El arte colectivo y político ciberfeminista mexicano. Mujeres en la red @: http://www.mujeresenred.net /spip.php?article982 [octubre 2007].

Real Academia de la Lengua Española. Diccionario de RAE. Avance de la 23 a ed. @: www.drae.es [octubre 2007].

Springer, J. M. 2000. El que a Hierro mata....Réplica 21 @: http://www.replica21.com/archivo/articulos/s_t/ 024_springer_wolfer.html [octubre 2007].

Terán TBWA. Página web de la agencia publicitaria @: http://www.terantbwa.com.mx [octubre 2007]

Weinrich U., W. Labov y M. Herzog. 1968. Empirical Foundations for a Theory of Language Change. En: Lehmann, W.P. Directions for Historical Linguistics. Austin-Londres: University of Texas. pp. 95-188. 


\section{Apéndice: Lemas de la campaña Soy totalmente Palacio (1997-2007)}

1997

Porque un psicoanalista nunca entenderá el poder curativo de un vestido nuevo.

Porque sólo una buena esposa evita ir mucho de compras.

Porque la mejor forma de guardar la línea es comer con los ojos.

Porque nadie ha logrado envasar el olor a nuevo.

1998

Hay dos cosas que una mujer no puede evitar, llorar y comprar zapatos.

Sólo una frase separa a la niña de la mujer: "no tengo nada que ponerme".

Lo curioso es que lo que Ama un Ama de casa son las tiendas.

A las mujeres siempre nos sobran kilos y nos falta ropa.

Es más fácil conquistar a un hombre que a un espejo.

1999

Cada vez hay menos príncipes; por fortuna, cada vez hay más Palacios.

$\mathrm{El}$ amor a primera vista existe. Basta pararse frente a un escaparate.

El problema no es que me quede bien o mal, sino que ya me lo vieron.

Ningún hombre conoce la respuesta correcta a: "¿me quieres?" y "¿cómo me veo?"

Por suerte somos el Sexo Débil, el fuerte es el que carga las compras.

Las mujeres tenemos el vicio de comprar y es que no podemos ser perfectas.

2000

La prueba de que no somos superficiales, es que también nos preocupa nuestro interior.

Si preguntas mi talla, preferiré contestar mi edad.

Lo maravilloso de las tiendas es que siempre encuentras, lo que no andas buscando.

Yo sé cómo me veo. Si pregunto es para saber cuánto te gusto.

¿Quién es la vanidosa, la que se arregla o la que cree que así está bien?

2001

Si las paredes oyen, imagínate si los probadores hablaran.

La ropa cubre lo que eres y descubre lo que quieres ser.

Si las medias supieran la angustia que causan cuando se van, quizá regresarían.

Si te vistes para matar, prepárate para ver a alguien morir de amor.

Las mujeres queremos más que los hombres, por eso compramos más.

Sólo estoy viendo, en realidad quiere decir "no me despierten, estoy soñando".

2002

Si las mujeres no fueran de compras, los hombres no tendrían calcetines.

Si te digo que no me pasa nada, o no tengo nada, no me creas nada.

Ninguna mujer sabe lo que quiere, hasta que se lo ve puesto a otra.

$\mathrm{Ni}$ un hada madrina te saca de tantos apuros como un vestido negro.

Las tiendas existen porque la vanidad nunca muere.

2003

Te daría mi vida pero la estoy usando.

La firma de un diseñador es como el amor: no se puede ocultar.

Jamás estás ni demasiado bien vestida, ni demasiado amada.

2004

Soy talla 3: no hay rival que se resista a eso.

No lo olvides: lo tuyo es mío y lo mío es mío.

2005

Una mujer no sabe lo que quiere hasta que un diseñador se lo dice.

Quizá no me vaya al cielo pero un par de tacones me acercan. soy totalmente palacio.

2006

Te lo dije: soy Totalmente Palacio.

Los caballeros no tienen memoria pero nunca olvidan un buen perfume.

Las mujeres siempre supimos que un cambio de ropa nos hace poderosas.

2007

Si estas viva, vive Totalmente Palacio.

Nunca antes una mujer quiso tanto a un hombre. Y sí somos Palacio. 